\title{
WHO reforms long overdue, critics say
}

$\mathrm{B}$ udget and staff cuts are compelling the World Health Organization (WHO) to narrow its focus, a move that many observers of the organization say is long overdue.

The global experts also say that the WHO needs to essentially redefine and reposition itself within the increasingly complex and convoluted field of global health. The experts suggest that the world will not suffer if the WHO cuts certain programs while narrowing its focus. Many other health organizations have been created to address particular health concerns, such as HIV/AIDS, since the WHO formed in 1948.

There were an estimated 40 bilateral donors, 26 United Nations agencies, 20 global and regional funds, 90 global health initiatives, more than 14000 global health missions, as well an untold number of not-for-profit organizations, charities, product development partnerships and other agencies operating in 54 recipient countries in 2008, with a collective annual budget of US\$22 billion (www.cmaj.ca/lookup /doi/10.1503/cmaj.109-3701).

"They need to take a hard look at what's out there on the global landscape these days and see what their role should be," says Amanda Glassman, director of global health policy at the Center for Global Development, a nonprofit think tank based in Washington, DC. "They do good work, but they have to try to focus and convey that focus more clearly. They also have to develop a financial model that leaves them less vulnerable."

Currently, the Switzerland-based WHO receives money from two sources: member state contributions for its regular budget and voluntary donations for targeted initiatives, with the latter traditionally accounting for nearly $80 \%$ of its funding. In recent years, however, rich donor nations have reduced their contributions as they struggled to handle the effects of the global economic recession.

A factor compounding the financial problem is the large portion of donations that are made in US dollars, a cur- rency that in recent years has performed poorly against the Swiss Franc. As a result of the financial woes, the WHO's biennial budget for 2012-13 will be US $\$ 1$ billion lower than its 2010-11 budget of \$US4.5 billion. The organization plans to cut 300 jobs at its Geneva headquarters, reducing staff there to 2100 people.
"The stronger Swiss franc makes our operations much more expensive, and our purchasing power has declined by about a fifth," says Christy Feig, WHO's director of communications. "We have to focus on our priorities."

But what should those priorities be?

Well, there are plenty of people with opinions on that topic. For decades, the

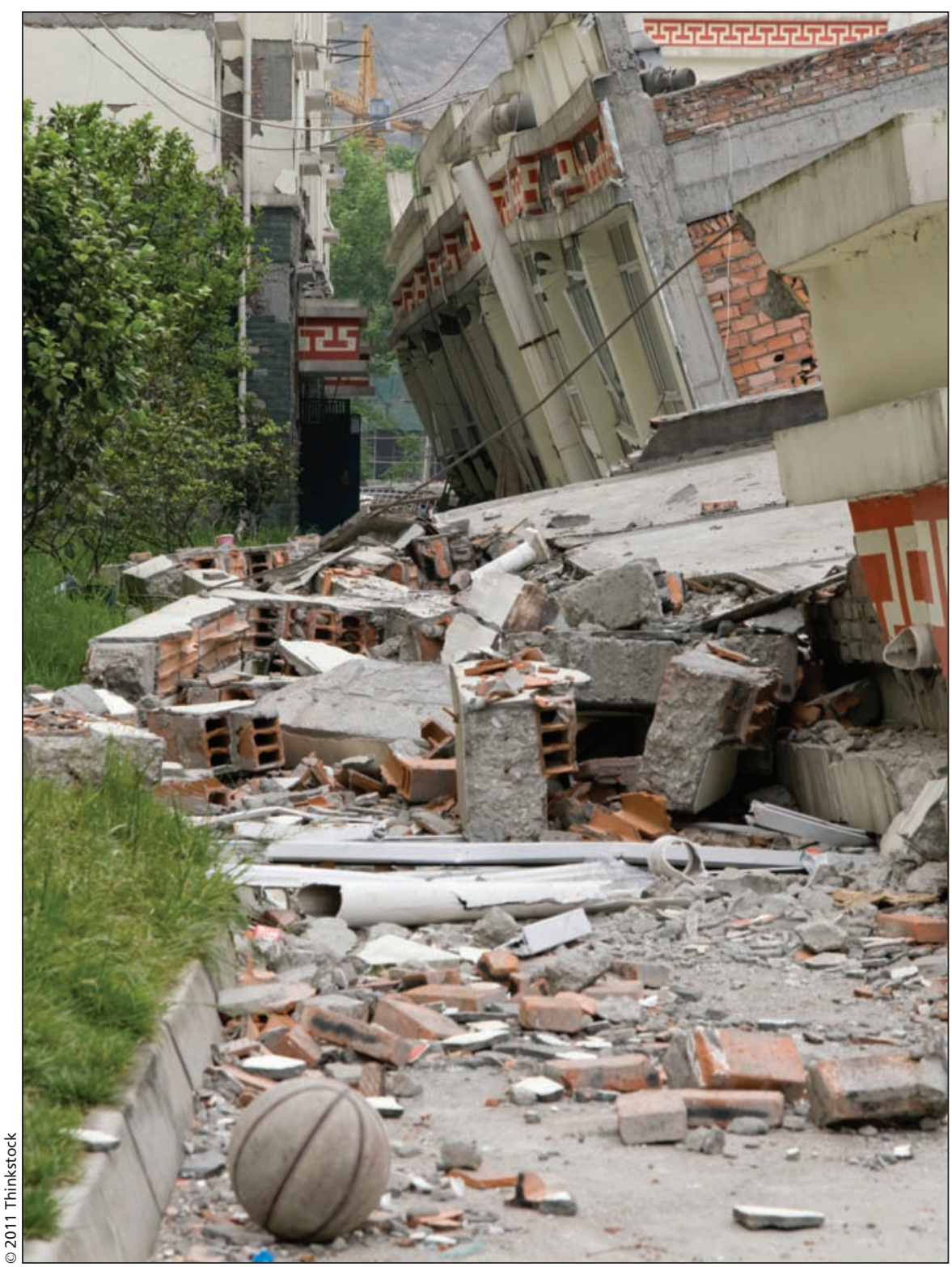

After an earthquake struck Sichua, China, in 2008, the WHO helped the area mitigate risk factors for communicable disease transmission. Disaster response is one of the core strengths that the organization should focus on in light of its current financial struggles, say some global health experts. 
WHO has come under widespread criticism for having become an unwieldy, top-heavy, bureaucratic monstrosity that does many things poorly and few things well. Calls for reform have been frequent.

In 2002, the WHO was slagged as a "bureaucracy for bureaucracy's sake, mired in useless statement-making and conference-giving" (http://reason.com /archives/2002/01/01/who-cares). The harsh editorial argued that WHO had errantly shifted away from health into the realm of politics, taking on issues such as social inequality, and that the health concerns it did address were most pertinent to richer nations, such as increasing seat belt use, at the expense of the world's poor and sick. "Since the WHO's funding is mostly from First World governments, making them its relevant 'customer base,' it caters to First World concerns. WHO's recent history has been a vivid example of bureaucratic creep. In expanding its purview far beyond merely medical, WHO is trying to stave off extinction."

In previous commentaries, $\mathrm{WHO}$ has been accused of suffering from such deficiencies as weak leadership and petty corruption (BMJ 1994;309:1424), and of being overstaffed and overcommitted (BMJ 1995;310:543-4).

Even WHO's leaders are now pointing out shortcomings. In a recent report, WHO Director-General Dr. Margaret Chan wrote that the organization has done a poor job of strategically setting priorities, is duplicating work done by other health organizations and is too rigid to rapidly adapt to challenges (http://apps.who.int/gb/ebwha/pdf_files /WHA64/A64_4-en.pdf).
"At the end of the decade, WHO finds itself overcommitted, overextended, and in need of specific reforms," wrote Chan.

To turn things around, the WHO needs to leverage its core strengths, according to a report from the Washington, DC-based Center for Strategic and International Studies (http://csis.org/files /publication/110502_Reeves_Leveraging WHO_Web.pdf). Traditionally, those strengths have been in four areas: public health surveillance, preparedness and disaster response; global standard setting and regulation; creating global partnerships to address emerging health priorities; and advocating for policy and behaviour change to combat noncommunicable diseases.

In a world of global pandemics and borderless health threats, a focused WHO is more important than ever, the report states: "Transnational disease threats of this magnitude are simply beyond the scope of a bilateral response and require the pooled resources, expertise and networks that WHO is well positioned to provide."

The WHO should also focus on solving the health problems of its member states, rather than focusing on the priorities of nations that are large donors, according to Dr. Martin McKee, professor of European public health at the London School of Hygiene \& Tropical Medicine in the United Kingdom.

"The WHO is the servant of its member states, so its priorities must reflect their priorities. However, this means that they must give it the resources to follow them through," McKee writes in an email. "WHO has two main roles, devel- oping global norms and standards and providing assistance to its member states. Unless the member states are prepared to increase their core funding, then I fear it will have to concentrate on the former, where it has no competitor, rather than the latter, where there are many other players."

WHO's budgetary allocations are "heavily skewed toward infectious diseases" McKee and others have argued (Lancet 2008;372:1563-9). In 2006-07, WHO devoted $87 \%$ of its budget to combating infectious diseases, $12 \%$ to fighting noncommunicable diseases and $1 \%$ to injuries and violence. The analysis also found that often-earmarked funding from donor nations was "misaligned with the health needs of the main recipients of the WHO's activities."

"There was closer alignment to actual burdens of diseases in the regular budget," says David Stuckler, a lecturer in sociology at the University of Cambridge in the United Kingdom, who also contributed to the budget analysis.

Glassman says WHO needs to consider a new financial model. According to one recent paper, that model should include such changes as increases to member state contributions or $20 \%-30 \%$ overheads on voluntary donations to supplement the core budget (JAMA 2011; 305:1585-6).

The organization also needs donor nations to set aside national interests. They also "need to manage their finances in a more strategic, integrated way." Roger Collier, CMAJ

CMAJ 2011. DOI:10.1503/cmaj.109-3933

\section{Value of e-prescribing questioned}

$\mathrm{D}$ ecades after Canada's 33700 pharmacists began buying computers in the expectation that provincial health systems would connect them with physicians through electronic prescription networks, such information sharing may be inching toward becoming a reality.

Although skeptics say the primary rationale for such networks - reduced prescription errors and expedited dispensing - may be based on exagger- ated evidence, Canada Health Infoway, the federally-funded not-for-profit organization responsible for developing electronic health records, is urging more rapid progress toward e-prescribing.

Four provinces now conform to Infoway's national technical standards for drug information systems, Kirk Ferguson, vice-president, corporate affairs, writes in an email. "Infoway achieved $98 \%$ of its target to achieve electronic capture of information from

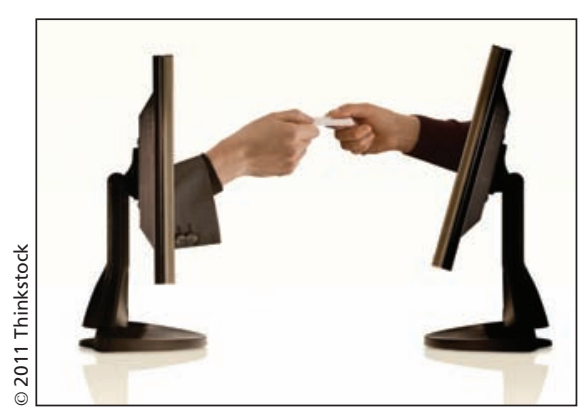

While several provinces have built centralized drug information systems that theoretically allow e-prescribing, there are few doctors in Canada who are electronically transmitting prescriptions to pharmacies. 